\title{
Preclinical toxicological evaluation of measles virus vaccine strain in non-human primates: A two-month intravenous study
}

\author{
Dang Thanh Chung ${ }^{1 \#(}$, Ho Thi Long ${ }^{2 \#, ~ H o a n g ~ V a n ~ T o n g ~}{ }^{1,3}$, Ngo Thu Hang ${ }^{1}$, Ngo Thu Huong ${ }^{4}$, Bui Khac \\ Cuong ${ }^{1}$, Pham Van Tran², Nguyen Thuy Linh ${ }^{5}$, Nguyen Dang Hien ${ }^{4}$, Can Van Mao ${ }^{1}$, Nguyen Duc Thuan ${ }^{6}$, \\ Nguyen Linh Toan ${ }^{1}$, Nguyen Thanh Tung ${ }^{7, *}$, Ho Anh Son ${ }^{1,3, *}$
}

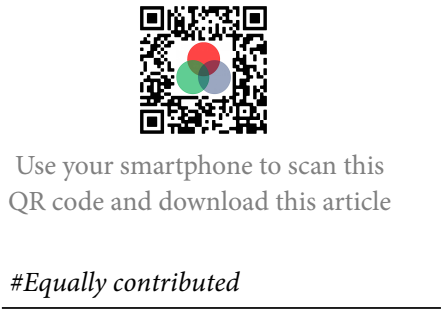

${ }^{1}$ Department of Pathophysiology, Vietnam Military Medical University, Hanoi, Viet Nam

${ }^{2}$ Department of Biochemistry, 103 Military Medical Hospital, Vietnam Military Medical University, Hanoi, Viet Nam

${ }^{3}$ Institute of Biomedicine \& Pharmacy, Vietnam Military Medical University, Hanoi, VietNam

${ }^{4}$ Centre for Research and Production of Vaccines and Biology (POLYVAC), Hanoi, Viet Nam

${ }^{5}$ Department of Pathology, 103 Military Medical Hospital, Vietnam Military Medical University, Hanoi, Viet Nam

${ }^{6}$ Department of Neurology, Military Hospital 103, Vietnam Military Medical University

${ }^{7}$ Military Institute of Clinical Embryology and Histology, Vietnam Military Medical University, Hanoi, Vietnam

History

- Received: Apr 29, 2021

- Accepted: Jun 21, 2021

- Published: Jun 30, 2021

DOI : 10.15419/bmrat.v8i6.676

\section{Check for updates}

\section{Copyright}

(๑) Biomedpress. This is an openaccess article distributed under the terms of the Creative Commons Attribution 4.0 International license.

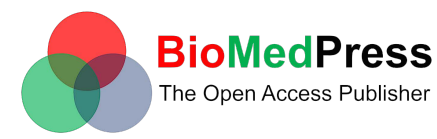

\begin{abstract}
Introduction: Based on its ability to kill tumor cells, the vaccine strain of the measles virus is used for oncolytic virotherapy. However, the dose required for cancer therapy is much higher than that used for vaccination. Therefore, this study was conducted to evaluate the preclinical toxicology of the vaccine strain of measles virus in monkeys. Methods: 16 healthy Macaca mulata monkeys were randomly divided into four groups, of which one was a control. A preclinical safety evaluation of the vaccine strain of the measles virus was performed, and the three experimental groups were intravenously injected with the strain at doses of $10^{5}$ TCID50, $10^{6}$ TCID50 and $10^{7}$ TCID50 respectively. Results : There were no significant abnormalities in the physical, clinical, haematological, and biochemical parameters following the intravenous injection with measles vaccine at doses of $10^{5} \mathrm{TCID} 50,10^{6} \mathrm{TCID} 50$ and $10^{7} \mathrm{TCID} 50$. The vaccine strain of measles virus remained in the plasma until the 30th day and disappeared on the 60th, and it did not persist in the tissues on days 30 and 60 post injection. Measles IgG antibody was negative on days $0,1,3$, and 8 and was positive on days 15,30 , and 60 post administration of the measles virus. The histopathology of target organs was not affected in all groups on days 30 and 60 post injection. Conclusions: The systematic preclinical safety data of the present study confirms the safety of two months of concentrated measles vaccine administration in the Macaca mulata monkey for clinical trials.
\end{abstract}

Key words: concentrated measles vaccine, preclinical toxicology, Macaca mulata monkey

\section{INTRODUCTION}

Oncolytic viruses (OLVs) have been used to effectively treat several cancers due to their ability to replicate and break down cancer cells and/or stimulate the immune system to respond against tumours ${ }^{1}$. Recently, many vaccines for preventing infectious diseases have been repurposed for use in cancer treatments, of which the measles vaccine strain has shown great potential in anticancer activities against different malignancies ${ }^{2}$. The effectivness of OLVs in cancer treatment has been established in preclinical studies and clinical trials, and several OLVs have been approved by the US Food and Drug Administration (FDA) for clinical practice ${ }^{3}$. The vaccine strain of the measles virus $(\mathrm{MeV})$ is one of the most highly effective OLVs for cancer treatment. MeV has previously been shown to have a great anticancer property in small animal models against different cancers such as laryngeal cancer ${ }^{4}$, human solid malignancies ${ }^{5}$, and human hematological cancers ${ }^{6}$. However, the $\mathrm{MeV}$ dose required for cancer treatment is much higher than that used for vaccination. Therefore, it is nec- essary to evaluate the preclinical safety and immunogenicity of the high-dose vaccine in experimental animals before employing the same in clinical practice. Attenuated $\mathrm{MeV}$ preparations are safe for the community and have been used as vaccines for over 50 years ${ }^{7}$. In Vietnam, the Centre for Research and Production of Vaccines and Biologicals (POLYVAC) has been producing effective, high-dose $\mathrm{MeV}$ vaccines that meet community cancer treatment requirements and standards.

The attenuated $\mathrm{MeV}$ strains use the CD46 receptor to enter both human and monkey cells. Studies have showed that the measles infection process in monkeys is similar to that in humans ${ }^{7}$; therefore, monkeys are the most suitable animals for evaluating the safety and efficacy of the measles vaccine. Accordingly, the present study was conducted to evaluate the preclinical safety of $\mathrm{MeV}$ in monkeys by assessing the physical, clinical and histopathological profiles of the target organs.

\section{METHODS}

Cite this article : Thanh Chung D, Thi Long H, Van Tong $\mathrm{H}$, Thu Hang N, Thu Huong N, Khac Cuong B, Van Tran P, Thuy Linh N, Dang Hien N, Van Mao C, Duc Thuan N, Linh Toan N, Thanh Tung N, Anh Son H. Preclinical toxicological evaluation of measles virus vaccine strain in non-human primates: A twomonth intravenous study. Biomed. Res. Ther.; 8(6):4382-4393. 


\section{Correspondence}

Nguyen Thanh Tung, Military Institute of Clinical Embryology and Histology, Vietnam Military Medical University, Hanoi, Vietnam

Email: tung_ttcnp@yahoo.com

Correspondence

Ho Anh Son, Department of Pathophysiology, Vietnam Military Medical University, Hanoi, Viet Nam

Institute of Biomedicine \& Pharmacy, Vietnam Military Medical University, Hanoi, VietNam

Email: hoanhsonhp@gmail.com

\section{Ethical statement}

All experimental animal procedures were conducted according to the Institutional Animal Care and Use guidelines. The study protocols were approved by the Ethical Committee of the Vietnam Military Medical University (VMMU).

\section{Vaccine strain of measles virus}

The vaccine strain of $\mathrm{MeV}$ was produced by POLYVAC. Live measles vaccine of the AIK-C strain was produced in Vietnam, according to the technology transfer from the Kitasato Institute, Japan. Moreover, the vaccines produced by POLYVAC (PolyVac I and II) showed a high immunogenicity in two clinical trials in Vietnam ${ }^{8}$. The vaccine used for cancer treatment purpose was concentrated at doses of $10^{5}$ TCID50, $10^{6}$ TCID50, $10^{7}$ TCID50.

\section{Study design}

The research was carried out at Rua Island in Bai Tu Long Bay, Cam Pha City, Quang Ninh Province, particularly at the Department of Pathophysiology of Vietnam Military Medical University from August 2019 to May 2020. 16 monkeys (Macaca mulatta) of 2 years of age that weighed $2.5 \pm 0.2 \mathrm{~kg}$ and were negative with measles IgG antibodies (confirmed by ELISA) were chosen for this study, irrespective of sex. The monkeys were raised in semi-natural conditions, kept in separate houses, and fed appropriate diets. During the quarantine period, monkeys were fed with peanuts, fresh vegetables, and seasonal fruits. They were then equally and randomly divided into four groups: one control group and three experimental groups that were injected with the measles vaccine at doses of $10^{5}$ TCID50, $10^{6}$ TCID50, $10^{7}$ TCID50 respectively. All the monkeys were administered a single dose through the small saphenous vein. Data on the study parameters were collected before injection (day 0 ) and on days 1, 3, 8, 15, 30 and 60 post injection. On day 30 and 60 post injection, eight animals were randomly selected (two per group/dose) and given an intramuscular injection of ketamine $\mathrm{HCl}$ [15 mg/kg]), following which they were euthanised (administering thiopentone sodium $[100 \mathrm{mg} / \mathrm{kg}]$ ). Tissues were collected from various organs, including the brain, salivary, lungs, heart, liver, kidneys, and spleen, for histopathological examination and measles virus detection.

\section{Overall health status}

The animals were checked and examined for behavioural abnormalities daily, and their body weights and temperatures were recorded. Skin, mucosa, and conjunctiva were observed and examined for any abnormalities in the morning at each timepoint.

\section{Clinical laboratory investigations}

Blood samples were collected on days 0 and 1, 3, 8, 15,30 , and 60 post injection. The haematology profile included red blood cell (RBC), total white blood cell (WBC), and platelet counts as well as haemoglobin $\mathrm{Hb})$ levels. The parameters were analysed via an automated blood cell counter (Sysmex haematology testing machine, USA) using blood samples collected in EDTA K2 tubes. The laboratory parameters included plasma glucose, blood urea nitrogen, creatinine, total protein, albumin, aspartate aminotransferase (AST), alanine aminotransferase (ALT), and cholinesterase; these were estimated using an autoanalyser (AU640, Beckman Coulter, USA). The quality control samples supplied by Wipro Biomed were used to establish the precision and accuracy of the analyses.

\section{Nested PCR for detection of measles virus in plasma and tissues}

For $\mathrm{MeV}$ detection, plasma samples of the monkeys on days $1,3,8,15,30$ and 60 post injection and tissue samples from the brain, salivary, lungs, heart, liver, kidneys, and spleen on days 30 and 60 post injection were collected. Total RNA was isolated from the plasma and tissues using an RNA purification kit (Thermo Scientific, K0731) and employed as a template for cDNA synthesis using the RevertAid First Strand cDNA synthesis kit (Thermo Scientific, K1622). The synthesised cDNA was subsequently subjected to nested RT-PCR. The first-step of RT-PCR using primers (NBE-MAS: 5'-GAT CCA GAC TTC TGG CCG G-3' and NDE-MAS: GAA TCA GCT GCC GTG TCT GG-3') amplified a 430bp fragment of DNA. The second step of the PCR using another set of primers (NAE-MAS: 5'-GGA GTC TCC AGG TCA ATT GA-3' and NCE-MAS: 5'-TCC TTG TTC TCG AAC CAT CC-3') amplified a 250bp fragment. PCR reactions were performed at Agilent Technologies SureCycler 8800 (Malaysia) using a DreamTag Hot Start PCR Master Mix (Thermo Scientific, K9011), according to the manufacturer's instructions. Thermal conditions for the first step of the nested PCR involved denaturation at $94{ }^{\circ} \mathrm{C}$ for 4 minutes and then at $94^{\circ} \mathrm{C}$ for 35 cycles of 30 seconds, annealing at $52{ }^{\circ} \mathrm{C}$ for 35 seconds, and extension at 72 ${ }^{o} \mathrm{C}$ for 45 seconds. Thermal conditions for the second step involved denaturation at $94{ }^{\circ} \mathrm{C}$ for 4 minutes and 
then at $94{ }^{\circ} \mathrm{C}$ for 40 cycles of 30 seconds, annealing at $50{ }^{\circ} \mathrm{C}$ for 35 seconds, and extension at $72{ }^{\circ} \mathrm{C}$ for 45 seconds. A polishing cycle at $72{ }^{\circ} \mathrm{C}$ for 5 minutes was used for the final extension. Amplicons were separated in $2 \%$ agarose gels with TBE buffer and visualised via GoldView staining (Solarbio, China). A 50bp DNA ladder (New England, Biolab, N3236S) was used as the molecular weight marker.

\section{Detection of measles virus-specific IgG an- tibody}

We used the Monkey Measles Virus Antibody IgG ELISA Kit (Melsin, EKMON-0083, China) to detect measles IgG antibody in monkey serum preexperiment and on days 1, 3, 8, 15, 30 and 60 post injection. The samples, positive control, negative control, and HRP-conjugated antibody were added to each well of the provided microtiter plate, which had been pre-coated with antigen. After incubation and washing to remove the unbinding enzyme, chromogen solutions A and B were added. The OD was spectrophotometrically measured at a wavelength of $450 / 560 \mathrm{~nm}$. The presence of MeV IgG antibody in the samples was then determined by comparing the OD of the samples with the cut-off values.

\section{The pathological examinations}

The brain, salivary, lungs, heart, liver, kidneys, and spleen of the monkeys in each group on days 30 and 60 post injection were collected and preserved in $10 \%$ buffered neutral formalin. After a minimum of 24 hours of fixation, they were sampled and processed; paraffin blocks were made and $4 \mu \mathrm{m}$ sections obtained. The sections were stained with hematoxylin and eosin (HE) and examined under a light microscope. All deviations from normal histology were recorded and compared with the corresponding controls.

\section{Statistical analysis}

For the quantitative variables, mean and variance were calculated. The values before and after the concentrated measles vaccine injection were compared using a paired sample t-test; the values of each group were compared by using ANOVA. For all the statistical tests, $\mathrm{p}<0.05$ was considered statistically significant.

\section{RESULTS}

\section{Overall health status}

The physical activity and health statuses of monkeys infected with different doses of $\mathrm{MeV}\left(10^{5}-\right.$
$10^{7}$ TCID50) were examined. The results did not reveal any significant changes in body weight (Table 1), body temperature (Table 2), or food intake among the groups injected with different $\mathrm{MeV}$ doses. During the study, all the monkeys were healthy and showed no skin or mucous rashes or signs of disturbed consciousness, behaviour, or movement. These results indicated that the monkeys were indulging in normal physical activities.

\section{Clinical laboratory investigations}

The health status of each of the monkeys was examined by checking the laboratory parameters. The results showed that the haematological (Table 3) and biochemical parameters (Table 4) on days 0 and 1, 3, $8,15,30$ and 60 post injection were within the normal range. The difference in the clinical parameters between the groups was not statistically significant ( $p>$ 0.05 ). These results indicated that the monkeys were of good health.

\section{The presence of measles virus in plasma and tissues}

To examine whether MeV was persistent in the bodies of the monkeys post injection, we took plasma and tissue samples for viral detection via nested RT-PCR. The results demonstrated that $\mathrm{MeV}$ was present in the plasma of the monkeys until day 30 post injection and disappeared on day 60 (Figure 1). $\mathrm{MeV}$ was not present in the tissues of monkeys on day 30 or day 60 after intravenous injection (Figure 2). These results indicate that the monkeys were infected with $\mathrm{MeV}$, and the viruses circulated for one month after the infection. 
Table 1: Body weights of monkeys (kg)

\begin{tabular}{ccccccc}
\hline Groups & \multicolumn{5}{c}{ Days } \\
& $\mathbf{0}$ & $\mathbf{3}$ & $\mathbf{8}$ & $\mathbf{1 5}$ & $\mathbf{3 0}$ & $\mathbf{6 0}$ \\
Control & $2.2 \pm 0.18^{(4)}$ & $2.2 \pm 0.18^{(4)}$ & $2.3 \pm 0.17^{(4)}$ & $2.4 \pm 0.10^{(4)}$ & $2.4 \pm 0.08^{(4)}$ & $2.6^{(2)}$ \\
$10^{5}$ TCID50 & $2.5 \pm 0.41^{(4)}$ & $2.2 \pm 0.18^{(4)}$ & $2.5 \pm 0.29^{(4)}$ & $2.4 \pm 0.40^{(4)}$ & $2.4 \pm 0.41^{(4)}$ & $3.1^{(2)}$ \\
$10^{6}$ TCID50 & $2.2 \pm 0.13^{(4)}$ & $2.3 \pm 0.13^{(4)}$ & $2.3 \pm 0.16^{(4)}$ & $2.3 \pm 0.26^{(4)}$ & $2.4 \pm 0.22^{(4)}$ & $2.9^{(2)}$ \\
$10^{7}$ TCID50 & $2.4 \pm 0,15^{(4)}$ & $2.3 \pm 0.15^{(4)}$ & $2.4 \pm 0.15^{(4)}$ & $2.4 \pm 0.08^{(4)}$ & $2.5 \pm 0.10^{(4)}$ & $2.7^{(2)}$ \\
\hline
\end{tabular}

Values are expressed as average or mean $\pm \mathrm{SD}$; Number in parentheses are number of animals. Comparing the weight among groups of monkeys with different vaccination doses at the research times, there was no difference $(p>0.05)$.

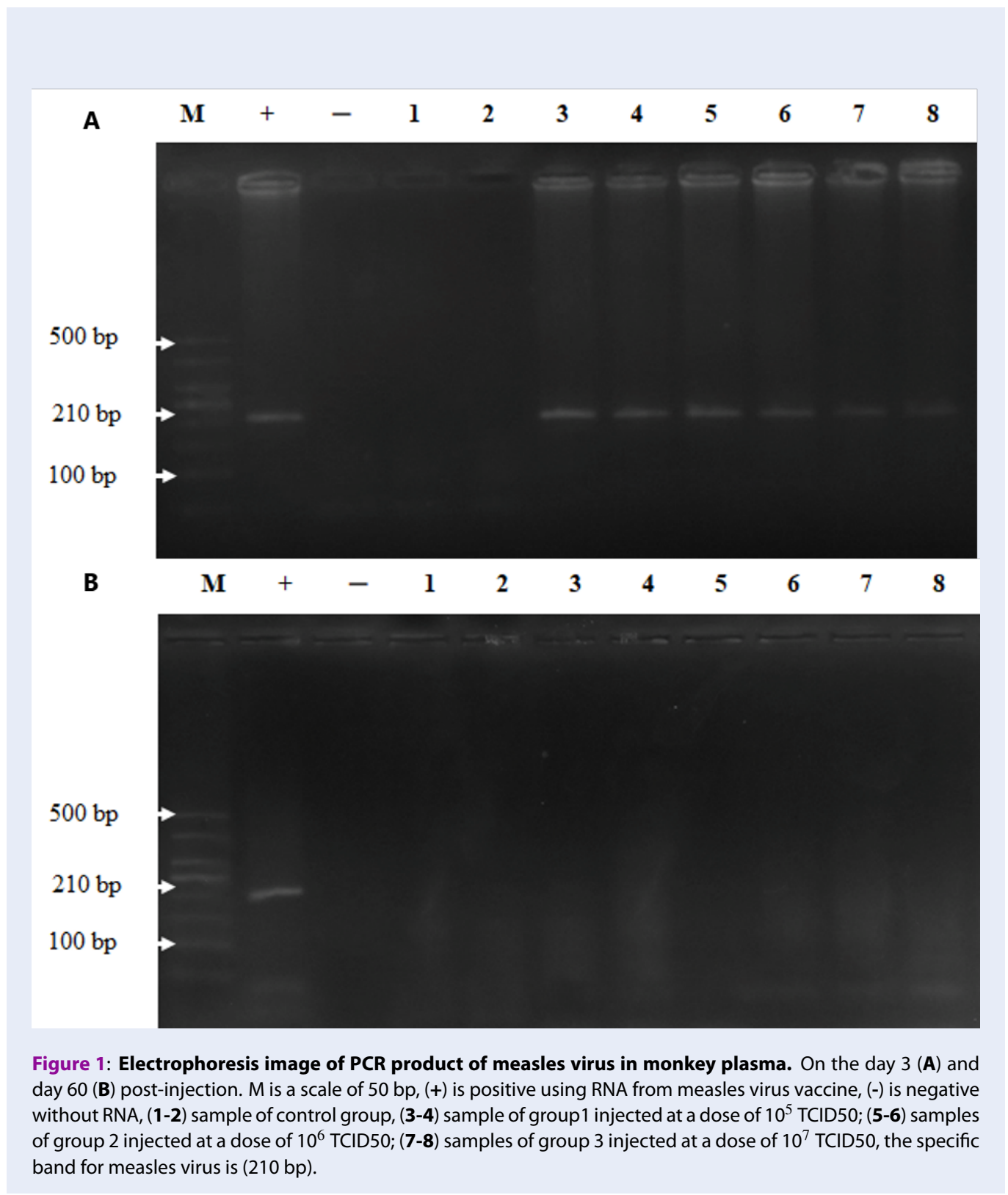




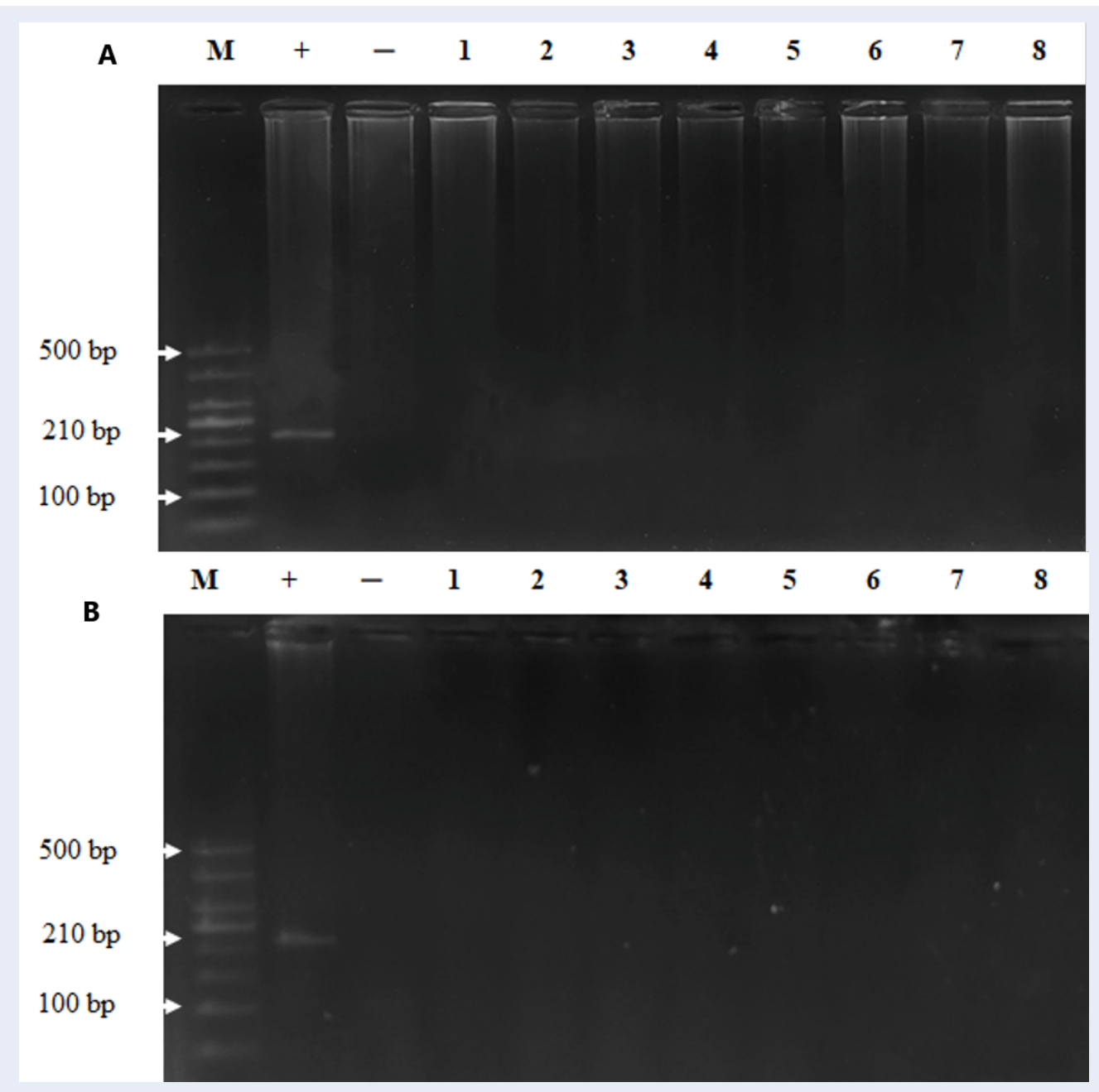

Figure 2: Electrophoresis image of PCR product of measles virus in spleen. On the day 30 (A) and day 60 (B) post-injection. $M$ is a scale of $50 \mathrm{bp},(+)$ is positive using RNA from measles virus vaccine, $(-)$ is negative without RNA, (1-2) sample of control group, (3-4) sample of group 1injected at a dose of $10^{5}$ TCID50; (5-6) samples of group 2 injected at a dose of $10^{6}$ TCID50; (7-8) samples of group 3 injected at a dose of $10^{7}$ TCID50, the specific band for measles virus is (210 bp).

Table 2: Body temperature of monkeys $\left({ }^{\circ} \mathrm{C}\right)$

\begin{tabular}{|c|c|c|c|c|c|c|c|}
\hline \multirow[t]{2}{*}{ Groups } & \multicolumn{7}{|c|}{ Days } \\
\hline & 0 & 1 & 3 & 8 & 15 & 30 & 60 \\
\hline Control & $39.0 \pm 0.13$ & $39.2 \pm 0.19$ & $\begin{array}{c}38.4 \pm \\
0.52^{(4)}\end{array}$ & $38.6 \pm 0.45$ & $\begin{array}{l}38.8 \pm \\
0.83^{(4)}\end{array}$ & $38.9 \pm 0.48$ & $39.3^{(2)}$ \\
\hline $10^{5}$ TCID50 & $39.1 \pm 0.28$ & $39.6 \pm 0.65$ & $\begin{array}{l}39.2 \pm \\
0.69^{(4)}\end{array}$ & $39.1 \pm 0.95$ & $\begin{array}{l}39.2 \pm \\
0.77^{(4)}\end{array}$ & $39.5 \pm 0.94$ & $39.6^{(2)}$ \\
\hline $10^{6}$ TCID50 & $39.1 \pm 0.21$ & $39.2 \pm 0.22$ & $\begin{array}{l}39.4 \pm \\
0.44^{(4)}\end{array}$ & $39.0 \pm 0.51$ & $\begin{array}{l}39.2 \pm \\
0.26^{(4)}\end{array}$ & $39.8 \pm 0.50$ & $39.3^{(2)}$ \\
\hline $10^{7}$ TCID50 & $39.3 \pm 0.28$ & $39.3 \pm 0.51$ & $\begin{array}{l}39.5 \pm \\
0.37^{(4)}\end{array}$ & $\begin{array}{l}39.4 \pm \\
0.59^{(4)}\end{array}$ & $\begin{array}{c}39.6 \pm 0.31 \\
(4)\end{array}$ & $39.7 \pm 0.36$ & $39.7^{(2)}$ \\
\hline
\end{tabular}

Values are expressed as average or mean $\pm \mathrm{SD}$; Number in parentheses are number of animals. Comparing the temperature among monkey groups with different vaccination doses at the research times, there was no difference $(\mathrm{p}>0.05)$ 
Table 3: Hematological parameters of monkeys

\begin{tabular}{|c|c|c|c|c|c|}
\hline Parameters & \multirow[t]{2}{*}{ Days } & \multicolumn{4}{|c|}{ Groups } \\
\hline \multirow{3}{*}{$\begin{array}{l}\mathrm{RBC} \times 10^{6} \\
/ \mu \mathrm{L}\end{array}$} & & Control & $10^{5}$ TCID50 & $10^{6}$ TCID50 & $10^{7}$ TCID50 \\
\hline & 0 & $6.2 \pm 0.73^{(4)}$ & $6.5 \pm 0.87^{(4)}$ & $6.0 \pm 0.49^{(4)}$ & $5.9 \pm 0.16^{(4)}$ \\
\hline & 1 & $5.9 \pm 0.43^{(4)}$ & $5.6 \pm 0.32^{(4)}$ & $5.9 \pm 0.42^{(4)}$ & $5.7 \pm 0.20^{(4)}$ \\
\hline \multirow{11}{*}{$\begin{array}{l}\text { WBC } \\
10^{3} / \mu \mathrm{L}\end{array}$} & 3 & $5.9 \pm 0.38^{(4)}$ & $5.5 \pm 0.32^{(4)}$ & $5.7 \pm 0.46^{(4)}$ & $5.6 \pm 0.41^{(4)}$ \\
\hline & 8 & $5.5 \pm 0.411^{(4)}$ & $5.4 \pm 0.25^{(4)}$ & $5.6 \pm 0.57^{(4)}$ & $5.2 \pm 0.40^{(4)}$ \\
\hline & 15 & $6.2 \pm 0.50^{(4)}$ & $6.5 \pm 1.05^{(4)}$ & $6.6 \pm 1.09^{(4)}$ & $6.2 \pm 1.02$ \\
\hline & 30 & $6.7 \pm 0.73^{(4)}$ & $6.8 \pm 1.66^{(4)}$ & $6.6 \pm 1.19^{(4)}$ & $6.9 \pm 1.13^{(4)}$ \\
\hline & 60 & $6.3^{(2)}$ & $6.4^{(2)}$ & $6.3^{(2)}$ & $6.9^{(2)}$ \\
\hline & 0 & $12.8 \pm 4.40^{(4)}$ & $12.3 \pm 5.80^{(4)}$ & $11.2 \pm 1.39^{(4)}$ & $12.6 \pm 5.52^{(4)}$ \\
\hline & 3 & $13.7 \pm 5.08^{(4)}$ & $13.2 \pm 3.39^{(4)}$ & $13.8 \pm 2.53^{(4)}$ & $12.8 \pm 4.98^{(4)}$ \\
\hline & 8 & $13.4 \pm 8.37^{(4)}$ & $11.2 \pm 1.40^{(4)}$ & $12.3 \pm 3.46^{(4)}$ & $13.5 \pm 4.09^{(4)}$ \\
\hline & 15 & $13.9 \pm 5.33^{(4)}$ & $13.1 \pm 3.78^{(4)}$ & $13.3 \pm 3.88^{(4)}$ & $13.6 \pm 2.59^{(4)}$ \\
\hline & 30 & $12.6 \pm 3.86^{(4)}$ & $13.2 \pm 3.84^{(4)}$ & $13.2 \pm 4.55^{(4)}$ & $12.7 \pm 4.45^{(4)}$ \\
\hline & 60 & $12.9^{(2)}$ & $13.0^{(2)}$ & $11.1^{(2)}$ & $11.7^{(2)}$ \\
\hline \multirow{7}{*}{$\begin{array}{l}\text { Platelets } \\
10^{3} / \mu \mathrm{L}\end{array}$} & 0 & $346.0 \pm 86.80^{(4)}$ & $414.5 \pm 62.81^{(4)}$ & $353.0 \pm 121.52^{(4)}$ & $440.2 \pm 154.73^{(4)}$ \\
\hline & 1 & $348.0 \pm 58.72$ & $418.3 \pm 87.20^{(4)}$ & $394.3 \pm 108.27^{(4)}$ & $462.7 \pm 131.18^{(4)}$ \\
\hline & 3 & $364.5 \pm 80.32^{(4)}$ & $438.5 \pm 98.02$ & $391.0 \pm 97.06^{(4)}$ & $426.5 \pm 129.43^{(4)}$ \\
\hline & 8 & $390.5 \pm 79.82$ & $492.8 \pm 161.62^{(4)}$ & $424.3 \pm 71.30^{(4)}$ & $420.0 \pm 174.01^{(4)}$ \\
\hline & 15 & $378.0 \pm 46.20^{(4)}$ & $409.8 \pm 128.23^{(4)}$ & $336.5 \pm 164.81^{(4)}$ & $454.5 \pm 151.92^{(4)}$ \\
\hline & 30 & $324.5 \pm 98.27^{(4)}$ & $470.2 \pm 107.60^{(4)}$ & $398.5 \pm 105.07^{(4)}$ & $401.2 \pm 129.99^{(4)}$ \\
\hline & 60 & $347.5^{(2)}$ & $378.0^{(2)}$ & $349.5^{(2)}$ & $422.5^{(2)}$ \\
\hline \multirow{7}{*}{$\begin{array}{l}\text { Hemoglobin } \\
(\mathrm{g} / \mathrm{l})\end{array}$} & 0 & $143.8 \pm 15.02$ & $147.5 \pm 17.43^{(4)}$ & $139.8 \pm 8.32^{(4)}$ & $134.8 \pm 3.43^{(4)}$ \\
\hline & 1 & $135.8 \pm 15.02$ & $126.5 \pm 2.86^{(4)}$ & $134.5 \pm 6.53^{(4)}$ & $129.8 \pm 2.27^{(4)}$ \\
\hline & 3 & $136.0 \pm 11.05^{(4)}$ & $125.3 \pm 3.75^{(4)}$ & $131.5 \pm 7.13^{(4)}$ & $128.0 \pm 3.73^{(4)}$ \\
\hline & 8 & $128.8 \pm 8.63^{(4)}$ & $125.6 \pm 3.79^{(4)}$ & $131.0 \pm 7.32^{(4)}$ & $128.0 \pm 3.73^{(4)}$ \\
\hline & 15 & $147.5 \pm 13.33^{(4)}$ & $148.5 \pm 16.89^{(4)}$ & $156.0 \pm 21.82^{(4)}$ & $159.5 \pm 23.82^{(4)}$ \\
\hline & 30 & $154.5 \pm 10.53^{(4)}$ & $151.5 \pm 30.63^{(4)}$ & $139.8 \pm 8.32^{(4)}$ & $134.8 \pm 3.43^{(4)}$ \\
\hline & 60 & $137.0^{(2)}$ & $135.0^{(2)}$ & $133.5^{(2)}$ & $136.5^{(2)}$ \\
\hline
\end{tabular}

RBC: Red blood cell, WBC: White blood cell.

Values are expressedas average or mean $\pm \mathrm{SD}$; Number in parentheses are number of animals.

The differences of RBC, WBC, Hemoglobin, Platelet count among monkey groups with different vaccination doses at the research times were not statistically significant $(\mathrm{p}>0.05)$ 
Table 4: Chemical parameters of monkeys

\begin{tabular}{|c|c|c|c|c|c|}
\hline \multirow[t]{2}{*}{ Parameters } & \multirow[t]{2}{*}{ Days } & \multicolumn{4}{|c|}{ Groups } \\
\hline & & Control & $10^{5}$ TCID50 & $10^{6}$ TCID50 & $10^{7}$ TCID50 \\
\hline \multirow{7}{*}{$\begin{array}{l}\text { Glucose } \\
(\mathrm{mmol} / \mathrm{l})\end{array}$} & 0 & $5.9 \pm 1.03^{(4)}$ & $5.4 \pm 1.58^{(4)}$ & $5.1 \pm 1.36^{(4)}$ & $5.0 \pm 0.82^{(4)}$ \\
\hline & 1 & $5.7 \pm 1.29^{(4)}$ & $5.6 \pm 0.62^{(4)}$ & $5.0 \pm 1.48^{(4)}$ & $5.4 \pm 1.75^{(4)}$ \\
\hline & 3 & $5.9 \pm 1.66^{(4)}$ & $5.5 \pm 2.43^{(4)}$ & $5.2 \pm 0.85^{(4)}$ & $4.9 \pm 1.06^{(4)}$ \\
\hline & 8 & $4.9 \pm 0.98^{(4)}$ & $5.0 \pm 0.24^{(4)}$ & $5.7 \pm 0.53$ & $4.9 \pm 0.50^{(4)}$ \\
\hline & 15 & $4.9 \pm 0.81^{(4)}$ & $5.8 \pm 1.10^{(4)}$ & $4.8 \pm 1.98^{(4)}$ & $4.7 \pm 1.15^{(4)}$ \\
\hline & 30 & $5.0 \pm 0.36^{(4)}$ & $5.0 \pm 0.69^{(4)}$ & $5.0 \pm 0.45^{(4)}$ & $4.7 \pm 0.59^{(4)}$ \\
\hline & 60 & $5.6^{(2)}$ & $5.3^{(2)}$ & $5.1^{(2)}$ & $5.0^{(2)}$ \\
\hline \multirow{7}{*}{$\begin{array}{l}\text { Ure } \\
(\mathrm{mmol} / \mathrm{l})\end{array}$} & 0 & $6.1 \pm 0.28^{(4)}$ & $6.1 \pm 0.28^{(4)}$ & $6.9 \pm 2.31$ & $6.6 \pm 1.23^{(4)}$ \\
\hline & 1 & $6.3 \pm 1.28^{(4)}$ & $6.9 \pm 1.27^{(4)}$ & $6.5 \pm 1.73^{(4)}$ & $6.5 \pm 1.49^{(4)}$ \\
\hline & 3 & $6.8 \pm 1.11^{(4)}$ & $6.8 \pm 1.13^{(4)}$ & $6.8 \pm 0.90^{(4)}$ & $6.2 \pm 0.87^{(4)}$ \\
\hline & 8 & $6.4 \pm 0.59^{(4)}$ & $6.5 \pm 1.68^{(4)}$ & $7.2 \pm 1.28^{(4)}$ & $6.3 \pm 1.61^{(4)}$ \\
\hline & 15 & $6.5 \pm 1.72^{(4)}$ & $6.5 \pm 1.85^{(4)}$ & $7.4 \pm 1.36^{(4)}$ & $6.5 \pm 1.11^{(4)}$ \\
\hline & 30 & $6.1 \pm 0.64^{(4)}$ & $7.1 \pm 2.14^{(4)}$ & $6.4 \pm 1.73$ & $7.0 \pm 1.17^{(4)}$ \\
\hline & 60 & $6.4^{(2)}$ & $7.2^{(2)}$ & $7.1^{(2)}$ & $6.4^{(2)}$ \\
\hline \multirow{7}{*}{$\begin{array}{l}\text { Creatinine } \\
(\mu \mathrm{mol} / \mathrm{l})\end{array}$} & 0 & $73.4 \pm 3.83^{(4)}$ & $83.3 \pm 10.49^{(4)}$ & $80.1 \pm 5.21$ & $72.3 \pm 13.25^{(4)}$ \\
\hline & 1 & $78.9 \pm 5.25^{(4)}$ & $87.4 \pm 6.61^{(4)}$ & $79.8 \pm 4.59^{(4)}$ & $81.8 \pm 8.33^{(4)}$ \\
\hline & 3 & $75.3 \pm 7.05^{(4)}$ & $81.0 \pm 8.30^{(4)}$ & $75.4 \pm 6.16^{(4)}$ & $81.2 \pm 9.17^{(4)}$ \\
\hline & 8 & $76.5 \pm 6.23^{(4)}$ & $84.7 \pm 7.41$ & $82.9 \pm 5.41$ & $80.4 \pm 6.00^{(4)}$ \\
\hline & 15 & $74.5 \pm 1.36^{(4)}$ & $74.6 \pm 6.58^{(4)}$ & $77.9 \pm 13.11$ & $72.5 \pm 6.93$ \\
\hline & 30 & $79.1 \pm 3.94(4)$ & $77.6 \pm 67.39^{(4)}$ & $77.3 \pm 12.87^{(4)}$ & $74.2 \pm 6.43^{(4)}$ \\
\hline & 60 & $70.6^{(2)}$ & $70.2^{(2)}$ & $71.1^{(2)}$ & $78.9^{(2)}$ \\
\hline \multirow{7}{*}{$\begin{array}{l}\text { Protein } \\
(\mathrm{g} / \mathrm{l})\end{array}$} & 0 & $77.0 \pm 2.02^{(4)}$ & $74.6 \pm 4.50^{(4)}$ & $77.8 \pm 9.06^{(4)}$ & $73.9 \pm 5.11^{(4)}$ \\
\hline & 1 & $79.0 \pm 2.67^{(4)}$ & $79.0 \pm 5.19^{(4)}$ & $72.5 \pm 3.25^{(4)}$ & $70.9 \pm 6.98^{(4)}$ \\
\hline & 3 & $72.8 \pm 4.89^{(4)}$ & $72.8 \pm 4.44^{(4)}$ & $73.3 \pm 2.71$ & $72.2 \pm 4.75^{(4)}$ \\
\hline & 8 & $72.1 \pm 1.17^{(4)}$ & $70.7 \pm 5.20^{(4)}$ & $74.4 \pm 3.88^{(4)}$ & $74.6 \pm 8.06^{(4)}$ \\
\hline & 15 & $74.3 \pm 5.30^{(4)}$ & $71.9 \pm 3.09^{(4)}$ & $75.6 \pm 0.92^{(4)}$ & $75.1 \pm 5.30^{(4)}$ \\
\hline & 30 & $71.3 \pm 3.38^{(4)}$ & $71.3 \pm 1.62^{(4)}$ & $70.6 \pm 4.15^{(4)}$ & $73.63 \pm 3.46^{(4)}$ \\
\hline & 60 & $69.3^{(2)}$ & $70.3^{(2)}$ & $73.7^{(2)}$ & $70.7^{(2)}$ \\
\hline \multirow{7}{*}{$\begin{array}{l}\text { Albumin } \\
(\mathrm{g} / \mathrm{l})\end{array}$} & & $40.7 \pm 5.12^{(4)}$ & $45.2 \pm 1.62^{(4)}$ & $46.3 \pm 5.10^{(4)}$ & $41.9 \pm 3.54^{(4)}$ \\
\hline & 1 & $42.6 \pm 4.42$ & $42.5 \pm 2.34^{(4)}$ & $41.7 \pm 3.34^{(4)}$ & $41.5 \pm 4.38^{(4)}$ \\
\hline & 3 & $42.2 \pm 1.88^{(4)}$ & $43.3 \pm 2.75^{(4)}$ & $42.5 \pm 2.46^{(4)}$ & $40.1 \pm 1.65^{(4)}$ \\
\hline & 8 & $41.7 \pm 1.82^{(4)}$ & $42.7 \pm 3.48^{(4)}$ & $43.7 \pm 3.12^{(4)}$ & $40.7 \pm 3.10^{(4)}$ \\
\hline & 15 & $43.7 \pm 2.88^{(4)}$ & $44.4 \pm 1.80^{(4)}$ & $45.5 \pm 2.49^{(4)}$ & $44.7 \pm 0.89^{(4)}$ \\
\hline & 30 & $40.9 \pm 6.64$ & $45.1 \pm 1.83^{(4)}$ & $45.1 \pm 2.49^{(4)}$ & $40.1 \pm 2.75^{(4)}$ \\
\hline & 60 & $39.5^{(2)}$ & $40.2^{(2)}$ & $45.1^{(2)}$ & $46.9^{(2)}$ \\
\hline \multirow[t]{7}{*}{ AST (U/l) } & 0 & $56.1 \pm 9.23^{(4)}$ & $57.1 \pm 13.04^{(4)}$ & $53.2 \pm 7.40^{(4)}$ & $53.2 \pm 5.19^{(4)}$ \\
\hline & 1 & $52.4 \pm 8.67^{(4)}$ & $51.8 \pm 4.82^{(4)}$ & $54.7 \pm 10.92$ & $55.8 \pm 9.07^{(4)}$ \\
\hline & 3 & $55.8 \pm 9.07^{(4)}$ & $56.2 \pm 6.55^{(4)}$ & $54.4 \pm 9.40^{(4)}$ & $57.1 \pm 7.66^{(4)}$ \\
\hline & 8 & $55.3 \pm 7.69^{(4)}$ & $55.8 \pm 5.82^{(4)}$ & $47.9 \pm 8.44^{(4)}$ & $49.8 \pm 9.69^{(4)}$ \\
\hline & 15 & $51.7 \pm 14.9^{(4)}$ & $50.6 \pm 2.28^{(4)}$ & $55.1 \pm 9.28^{(4)}$ & $55.3 \pm 9.72^{(4)}$ \\
\hline & 30 & $51.9 \pm 10.40^{(4)}$ & $52.5 \pm 9.69^{(4)}$ & $53.7 \pm 3.78^{(4)}$ & $52.2 \pm 12.7^{(4)}$ \\
\hline & 60 & $55.4^{(2)}$ & $57.1^{(2)}$ & $49.3^{(2)}$ & $48.8^{(2)}$ \\
\hline
\end{tabular}




\begin{tabular}{|c|c|c|c|c|c|c|}
\hline \multirow{14}{*}{ Table 4 continued } & ALT & 0 & $82.7 \pm 3.72^{(4)}$ & $85.6 \pm 3.29^{(4)}$ & $86.1 \pm 4.35^{(4)}$ & $84.3 \pm 2.81^{(4)}$ \\
\hline & $(\mathrm{U} / \mathrm{l})$ & 1 & $84.7 \pm 3.74(4)$ & $83.0 \pm 3.04^{(4)}$ & $86.9 \pm 4.56^{(4)}$ & $82.9 \pm 2.89^{(4)}$ \\
\hline & & 3 & $86.2 \pm 3.10^{(4)}$ & $84.3 \pm 2.29^{(4)}$ & $86.6 \pm 4.96^{(4)}$ & $85.7 \pm 2.99^{(4)}$ \\
\hline & & 8 & $82.2 \pm 2.70^{(4)}$ & $85.9 \pm 2.45^{(4)}$ & $83.9 \pm 4.76^{(4)}$ & $86.3 \pm 2.99^{(4)}$ \\
\hline & & 15 & $84.6 \pm 1.98^{(4)}$ & $84.7 \pm 3.79^{(4)}$ & $81.9 \pm 2.52^{(4)}$ & $86.1 \pm 3.79^{(4)}$ \\
\hline & & 30 & $85.3 \pm 3.73$ & $85.7 \pm 3.27^{(4)}$ & $83.9 \pm 4.36^{(4)}$ & $84.85 \pm 4.08^{(4)}$ \\
\hline & & 60 & $84.1^{(2)}$ & $80.2^{(2)}$ & $80.3^{(2)}$ & $83.0^{(2)}$ \\
\hline & $\begin{array}{l}\text { Cholinesteras } \\
(\mathrm{kU} / \mathrm{l})\end{array}$ & 0 & $13.3 \pm 2.15^{(4)}$ & $11.7 \pm 1.39^{(4)}$ & $11.2 \pm 2.60^{(4)}$ & $9.7 \pm 2.70^{(4)}$ \\
\hline & & 1 & $11.9 \pm 1.47^{(4)}$ & $10.4 \pm 3.04$ & $11.6 \pm 1.71$ & $10.2 \pm 1.40^{(4)}$ \\
\hline & & 3 & $13.8 \pm 2.14^{(4)}$ & $11.0 \pm 1.51^{(4)}$ & $9.8 \pm 1.63^{(4)}$ & $9.7 \pm 1.67^{(4)}$ \\
\hline & & 8 & $10.9 \pm 1.26^{(4)}$ & $11.1 \pm 2.01^{(4)}$ & $11.9 \pm 1.17^{(4)}$ & $11.1 \pm 3030^{(4)}$ \\
\hline & & 15 & $11.4 \pm 1.73^{(4)}$ & $10.7 \pm 1.580^{(4)}$ & $12.8 \pm 1.98^{(4)}$ & $11.0 \pm 2.40^{(4)}$ \\
\hline & & 30 & $11.2 \pm 3.91$ & $10.0 \pm 1.60^{(4)}$ & $12.8 \pm 0.78^{(4)}$ & $10.5 \pm 2.90^{(4)}$ \\
\hline & & 60 & $12.4^{(2)}$ & $10.4^{(2)}$ & $9.7^{(2)}$ & $10.3^{(2)}$ \\
\hline
\end{tabular}

Values are expressed as average or mean $\pm \mathrm{SD}$; Number in parentheses are number of animals.

The differences of glucose, ure, creatinine, protein, albumin, AST, ALT, cholinesterase among monkey groups with different vaccination doses at the research times were not statistically significant $(\mathrm{p}>0.05)$

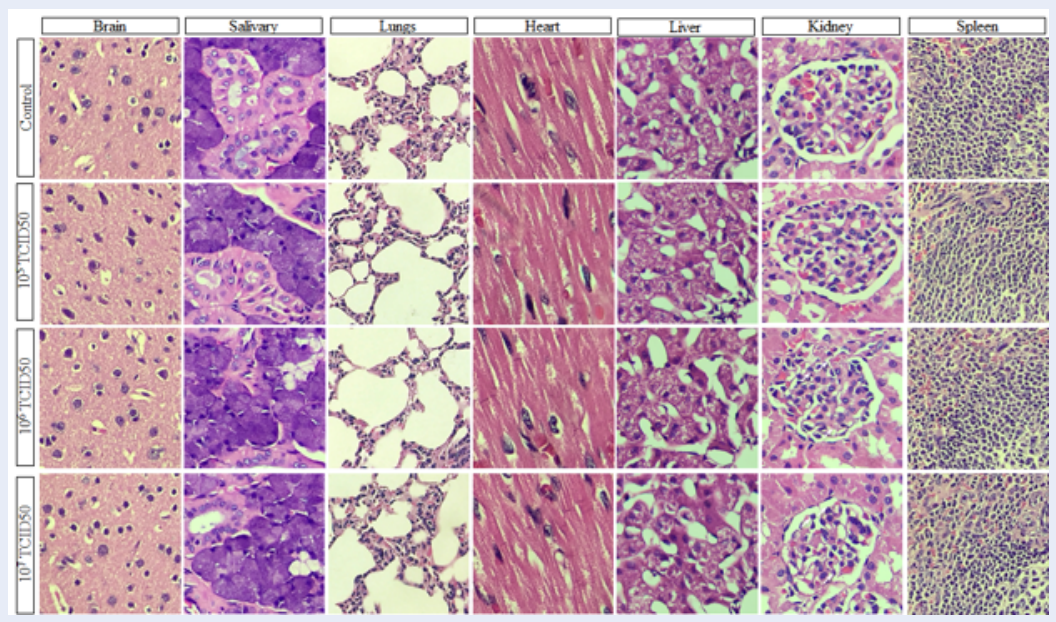

Figure 3: The histopathological examination of brain, salivary, lungs, heart, liver, kidney, and spleen of the control group and measles administration group at 30 day post-injection.

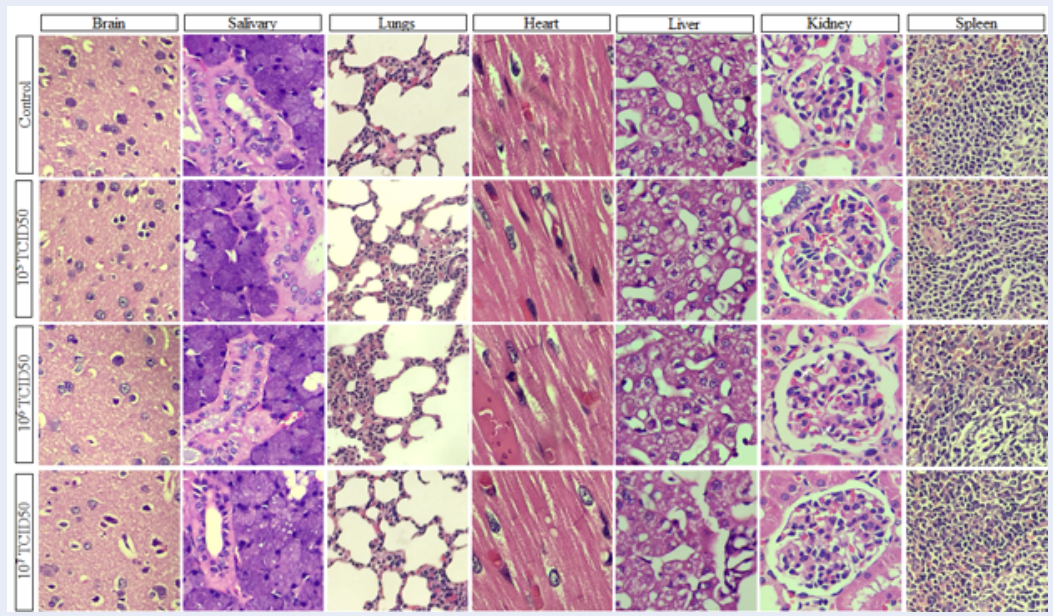

Figure 4: The histopathological examination of brain, salivary, lungs, heart, liver, kidney, and spleen of control group and measles administration group at 60 day post-injection. 
The presence of MeV IgG antibody in plasma

The vaccine activity of $\mathrm{MeV}$ and immune responses of the monkeys were subsequently checked. The MeVspecific IgG antibody was detected, and the results showed that monkeys in the control group were negative for $\mathrm{MeV}$ IgG antibody during the study. Monkeys injected with $10^{5}$ TCID50, $10^{6}$ TCID50, and $10^{7}$ TCID50 MeV were negative for MeV IgG antibodies on days $0,1,3$, and 8 and positive on days 15, 30, and 60 post injection (Table 4 ). This result indicates that $\mathrm{MeV}$ stimulated a specific immune response in the study monkeys.

\section{Histopathology of target organs}

Histiopathology was performed to check whether $\mathrm{MeV}$ may caused any damage in different organs (brain, salivary, lungs, heart, liver, kidneys, and spleen) during the persistence of the virus. No significant changes in the histopathology were observed between the control and measles administration groups, although different doses were present in the brain, salivary, lungs, heart, liver, kidneys, and spleen of the monkeys on days 30 (Figure 3) and 60 (Figure 4) post injection. These results suggest that $\mathrm{MeV}$ did not damage the organs of infected monkeys.

\section{DISCUSSION}

While the safety of attenuated $\mathrm{MeV}$ products has been proved, the actual vaccine dose used for cancer treatment is higher than that used for expanded immunization. Preclinical experiments have also demonstrated that extrapolating the data for clinical situations depends on species variation; therefore, species and dose selection constitute the primary requirement in preclinical toxicology studies. Selection of the species varies with the nature of the compound under study. Evaluating the safety of a new biological product depends on the species of the animal used ${ }^{9,10}$, affinity and level of receptor distribution with the biological product, dose, and timing employed ${ }^{9}$. To evaluate the safety of the concentrated measles vaccine, the Macaca mulatta monkey (non-human primate) species was selected because $95 \%$ of this primate's genome is similar to that of humans; moreover, the anatomical, physiological and immunological characteristics of monkeys are similar to that of humans. Notably, Macaca mulatta monkeys are highly susceptible to $\mathrm{MeV}$ infection and may develop pathological lesions and clinical symptoms similar to $\mathrm{MeV}$ infections in humans. A previous study showed that monkeys with $\mathrm{MeV}$ infections have some clinical presentations similar to those in humans, including rashes, mucositis and fever ${ }^{11}$. Our study found that Macaca mulatta monkeys infected with high doses of $\mathrm{MeV}$ showed no significant abnormalities in physical and laboratory examination, suggesting the safety of the $\mathrm{MeV}$ vaccine strain for cancer treatment purposes.

The $\mathrm{MeV}$ doses administered in this study were $10^{5}$ TCID50, $10^{6}$ TCID50, and $10^{7}$ TCID50, which made it challenging. The $\mathrm{MeV}$ doses have been effectively used for cancer treatment in our previous studies ${ }^{12}$ and also for human ovarian cancer treatment ${ }^{13}$, but these are higher than those used for vaccination (10 ${ }^{3}$ TCID50). The $\mathrm{MeV}$ doses in our study meet the WHO standards for animal vaccine testing practice $^{14}$. The results showed that there was no effect of $\mathrm{MeV}$ on the overall health status and haematological and biochemical parameters. This result is highly consistent with those of previous studies ${ }^{15-18}$, indicating the safety of $\mathrm{MeV}$ produced by POLYVAC for cancer treatment.

Our results showed that $\mathrm{MeV}$ remained in monkey plasma until day 30 post injection. Previous studies have showed that MeV-RNA exists until the recovery stage. The existence of MeV-RNA was first noted in a follow-up study of Zambian children with measles, in their tissues after their recovery from the disease ${ }^{19}$. Katz et al. (1962) showed that MeV-RNA can be detected from days 4 to 21 in infected monkeys ${ }^{20}$. Further, a study conducted on Macaca monkeys showed that the existence time of $\mathrm{MeV}$ depends on the vaccine dose ${ }^{11}$.

The mechanism by which MeV-RNA persists and the factors needed to eliminate viral RNA are unclear. $\mathrm{MeV}$ effectively inhibits the synthesis of IFN and IFN signals in virus-infected cells; this feature contributes to the persistence of MeV-RNA. Domain $\mathrm{C}$ of the $\mathrm{V}$ protein plays a role in inhibiting IFN synthesis. The transition from type 1 to type 2 in the response of $\mathrm{t}$-lymphocytes, with the production of regulatory $\mathrm{t}$ lymphocytes and cytokines, plays a role in MeV-RNA clearance. The binding of specific antibodies to $\mathrm{H}$ proteins reduces the expression of proteins on the surface of virus-infected cells. Antibodies may enhance the existence of $\mathrm{MeV}$-RNA by reducing the apoptosis and immune clearance of infected cells ${ }^{21}$. Prolonged existence of MeV-RNA is strongly associated with persistent infections and may explain immunological abnormalities after rash eradication, with lifelong immunity development specific to measles ${ }^{22}$. The fast clearance period is followed by a slow clearance period, and MeV-RNA cannot be detected although it can exist for a long time in lymphatic and other tissues. Past studies on RNA sequences of late-stage 
Table 5: Elisa test for Measles IgG antibody detection

\begin{tabular}{lcccccc}
\hline Group & \multicolumn{7}{c}{ Days } \\
& $\mathbf{0}$ & $\mathbf{3}$ & $\mathbf{8}$ & $\mathbf{1 5}$ & $\mathbf{3 0}$ & $\mathbf{6 0}$ \\
Control (positive/total) & $0 / 4$ & $0 / 4$ & $0 / 4$ & $0 / 4$ & $0 / 4$ & $0 / 2$ \\
$10^{5}$ CID50 (positive/total) & $0 / 4$ & $0 / 4$ & $0 / 4$ & $4 / 4$ & $4 / 4$ & $2 / 2$ \\
$10^{6}$ TCID50 (positive/total) & $0 / 4$ & $0 / 4$ & $0 / 4$ & $4 / 4$ & $4 / 4$ & $2 / 2$ \\
$10^{7}$ TCID50 (positive/total) & $0 / 4$ & $0 / 4$ & $0 / 4$ & $4 / 4$ & $4 / 4$ & $2 / 2$ \\
\hline
\end{tabular}

measles did not detect mutations in the $H$ and $N$ genes. The data available explains the long-term existence of MeV-RNA due to its slow clearance without mutation and ability to escape the immune system. The existence of RNA indicates that the low level of replication in tissues facilitates the maturation of the immune response to provide lifelong protection against reinfection. Further studies are needed to better understand the mechanism of MeV-RNA clearance $^{21}$.

In the present study, the MeV-RNA was detected in the plasma samples but not in the tissues up to day 30 post injection. This may be due to the amount of virus in the plasma being higher than in the tissue. The determination of the existence of $\mathrm{MeV}$ in organs at different times in experimental animals is important in clinical practice to determine the dose and the distance between the treatment cycles for patients with cancer. In our research, determining the existence of the virus after 30 days showed that $\mathrm{MeV}$ in the organs could no longer be detected. Therefore, it is necessary to conduct research with a larger sample size and determine the existence of $\mathrm{MeV}$ at an earlier stage with more timepoints.

Preclinical safety testing of vaccines involves not only the selection of appropriate species but also an assessment of the immunogenic potential of such preparations $^{23}$. Our results showed that IgG measles antibodies were positive on days 15,30 , and 60 post injection, which is consistent with other studies. Myers et al. showed that measles IgG antibodies appeared after 15 days $^{16}$. Rita et al. showed that the positive rates of IgG after 1 week, 2 weeks, 3 weeks and 4 weeks post-injection with Schwartz MeV were 0\%, 14\%, 81\% and $85 \%$ respectively ${ }^{24}$. Another study showed that $87 \%$ of monkeys were negative for IgG antibodies in the plasma 11 days post injection with MeV1-F4 and Rouvax vaccine. However, On day 29 after injection, $100 \%$ of monkeys vaccinated with Rouvax and MeV1F4 were found to have IgG antibodies in their plasma, suggesting that measles antibodies may not have been produced until day 11 after injection ${ }^{11}$. Our results showed that the MeV manufactured by POLYVAC has strong immunity.

$\mathrm{MeV}$ can cause organ damage in three ways: infection, viral replication, and immune response producing neurotoxic materials and allergic reactions(25). Therefore, high doses of $\mathrm{MeV}$ would probably induce toxicity of multiple organs. However, we observed non-significant histopathological changes in brain, salivary, lungs, heart, liver, kidneys, and spleen in the monkeys exposed to high therapeutic doses, suggesting the safety of the test material. The limitations of the current study are that the number of monkeys was quite small and the time of follow-up was short. Therefore, further research should be conducted with larger sample sizes, other primates, and longer follow-up periods.

\section{CONCLUSIONS}

There were no significant abnormalities in the physical, clinical, hematological, and biochemical parameters after the intravenous injections of high doses of measles vaccine. The vaccine strain of $\mathrm{MeV}$ existed in monkey plasma until day 30, and the measles IgG antibody could be detected after 15 days following injection. The viruses were not detected in the tissues and had no damaging effect on the target organs. Our systematic preclinical safety results indicate the safety of the concentrated measles vaccine for two months of clinical trials with Macaca mulata monkeys.

\section{ABBREVIATIONS}

ALT: Alanine aminotransferase

ANOVA: Analysis of variance

AST: Aspartate aminotransferase

CD46: Cluster of differentiation 46

DNA: Deoxyribonucleic Acid

EDTA: Ethylenediaminetetraacetic acid

ELISA: The enzyme-linked immunosorbent assay

FDA: US Food and Drug Administration

Hb: Haemoglobin

HE: Hematoxylin and Eosin

HRP: Horseradish peroxidase 
IFN: Interferon

MeV: Measles virus

OD: Optical density

OLVs: Oncolytic viruses

PCR : Polymerase chain reaction

POLYVAC: Centre for Research and Production

of Vaccines and Biology

RBC: Red blood cell

RNA: Ribonucleic acid

TBE: Tris borate EDTA

TCID50: The median tissue culture infectious dose

VMMU: Vietnam Military Medical University

WBC: White blood cell

WHO: World Health Organization

\section{ACKNOWLEDGMENTS}

All authors gratefully acknowledge the financial support from the Key scientific program state-level, Ministry of Science and Technology, Vietnam, code: KC10 /16-20 under grant number KC10.27/16-20.

\section{AUTHOR'S CONTRIBUTIONS}

DT Chung, HT Long, NT Tung, HA Son and NL Toan designed study. DT Chung, HT Long, HV Tong, NT Hang, NT Huong, BK Cuong, PV Tran, NT Linh, ND Hien, CV Mao, ND Thuan and NL Toan were involved in animal recruitment and sample collection. DT Chung and HT Long were involved in animal recruitment and sample collection, analyzed and interpreted the data. DT Chung, HT Long, HV Tong and NL Toan participated in drafting and writing the article. NT Tung and HA Son were involved in all aspects of the work through correspondence. All authors read and approved the final manuscript.

\section{FUNDING}

Ministry of Science and Technology, Vietnam, code: KC10 /16-20 under grant number KC10.27/16-20.

\section{AVAILABILITY OF DATA AND MATERIALS}

Data and materials used and/or analysed during the current study are available from the corresponding author on reasionable request.

\section{ETHICS APPROVAL AND CONSENT TO PARTICIPATE}

Not applicable.

\section{CONSENT FOR PUBLICATION}

Not applicable.

\section{COMPETING INTERESTS}

The authors declare that they have no competing interests.

\section{REFERENCES}

1. Marelli G, Howells A, Lemoine NR, Wang Y. Oncolytic Viral Therapy and the Immune System: A Double-Edged Sword Against Cancer. Frontiers in Immunology. 2018;9:866. PMID: 29755464. Available from: 10.3389/fimmu.2018.00866.

2. Vandeborne L, Pantziarka P, Nuffel AMV, Bouche G. Repurposing Infectious Diseases Vaccines Against Cancer. Frontiers in Oncology. 2021;11:688755. PMID: 34055652. Available from: 10.3389/fonc.2021.688755.

3. Guo C, Manjili MH, Subjeck JR, Sarkar D, Fisher PB, Wang $\mathrm{XY}$. Therapeutic cancer vaccines: past, present, and future. Advances in Cancer Research. 2013;119:421-75. PMID: 23870514. Available from: 10.1016/B978-0-12-407190-2. 00007-1.

4. Toan NL, Hang NT, Luu NK, Mao CV, Ba NV, Xuan NT. Combination of Vaccine Strain Measles Virus and Nimotuzumab in the Treatment of Laryngeal Cancer. Anticancer Research. 2019;39(7):3727-37. PMID: 31262899. Available from: 10. 21873/anticanres.13521.

5. Son HA, Zhang L, Cuong BK, Tong HV, Cuong LD, Hang NT. Combination of Vaccine-Strain Measles and Mumps Viruses Enhances Oncolytic Activity against Human Solid Malignancies. Cancer Investigation. 2018;36(2):106-17. PMID: 29485292. Available from: 10.1080/07357907.2018.1434539.

6. Hu S, Zhu W, Zhang LF, Pei M, Liu MF. MicroRNA-155 broadly orchestrates inflammation-induced changes of microRNA expression in breast cancer. Cell Research. 2014;24(2):254-7. PMID: 24080728. Available from: 10.1038/cr.2013.137.

7. Russell SJ, Peng KW. Measles virus for cancer therapy. Current Topics in Microbiology and Immunology. 2009;330:21341. PMID: 19203112. Available from: 10.1007/978-3-54070617-5_11.

8. Hien N, Luan LT, Huong NT, Thu NN, Thuy TH, Hoa NX. High immunogenicity of measles AIK-C vaccine produced in Vietnam. Eastern Journal of Medicine. 2011;16:199-207.

9. Weissinger J. Preclinical and pharmacology and toxicology of hematopoietic growth factors. Biotechnology Advances. 1989;7(3):387-99. PMID: 14542822. Available from: 10.1016/ 0734-9750(89)90181-X.

10. Chapman K, Pullen N, Graham M, Ragan I. Preclinical safety testing of monoclonal antibodies: the significance of species relevance. Nature Reviews Drug Discovery. 2007;6(2):120-6. PMID: 17268483. Available from: 10.1038/nrd2242.

11. Lorin C, Segal L, Mols J, Morelle D, Bourguignon P, Rovira O. Toxicology, biodistribution and shedding profile of a recombinant measles vaccine vector expressing HIV-1 antigens, in cynomolgus macaques. NaunynSchmiedeberg\{\&amp;\}\{\#\}x0027;s Archives of Pharmacology. 2012;385(12):1211-25. PMID: 22983013. Available from: 10.1007/s00210-012-0793-4.

12. Toan NL, Hang NT, Luu NK, Mao CV, Ba NV, Xuan NT. Combination of Vaccine Strain Measles Virus and Nimotuzumab in the Treatment of Laryngeal Cancer. Anticancer Research. 2019;39(7):3727-37. PMID: 31262899. Available from: 10. 21873/anticanres.13521.

13. Derycke MS, Pambuccian SE, Gilks CB, Kalloger SE, Ghidouche A, Lopez M. Nectin 4 overexpression in ovarian cancer tissues and serum: potential role as a serum biomarker. American Journal of Clinical Pathology. 2010;134(5):835-45. PMID: 20959669. Available from: 10.1309/AJCPGXK0FR4MHIHB.

14. WHO. Vaccine safety basic. 2013;;

15. Myers RM, Greiner SM, Harvey ME, Griesmann G, Kuffel MJ, Buhrow SA. Preclinical pharmacology and toxicology of intravenous MV-NIS, an oncolytic measles virus administered with or without cyclophosphamide. Clinical Pharmacology and Therapeutics. 2007;82(6):700-10. PMID: 17971816. Available from: $10.1038 /$ sj.clpt.6100409. 
16. Myers R, Harvey M, Kaufmann TJ, Greiner SM, Krempski JW, Raffel C. Toxicology study of repeat intracerebral administration of a measles virus derivative producing carcinoembryonic antigen in rhesus macaques in support of a phase I/II clinical trial for patients with recurrent gliomas. Human Gene Therapy. 2008;19(7):690-8. PMID: 18576918. Available from: 10.1089/hum.2008.035.

17. Allen C, Paraskevakou G, Liu C, lankov ID, Msaouel P, Zollman P. Oncolytic measles virus strains in the treatment of gliomas. Expert Opinion on Biological Therapy. 2008;8(2):213-20. PMID: 18194077. Available from: 10.1517/ 14712598.8.2.213.

18. de Swart RL, DeSwart R. Measles studies in the macaque model. Current Topics in Microbiology and Immunology. 2009;330:55-72. PMID: 19203104. Available from: 10.1007/ 978-3-540-70617-5_3.

19. Riddell MA, Moss WJ, Hauer D, Monze M, Griffin DE. Slow clearance of measles virus RNA after acute infection. Journal of clinical virology : the official publication of the Pan American Society for Clinical Virology. 2007;39(4):312-317. Available from: 10.1016/j.jcv.2007.05.006
20. Katz SL, Enders JF, Holloway A. The development and evaluation of an attenuated measles virus vaccine. Am J Public Health Nations Health. 1962;52(Suppl 2(2)):5-10. Available from: 10.2105/AJPH.52.Suppl_2.5.

21. Griffin DE, Lin WW, Nelson AN. Understanding the causes and consequences of measles virus persistence. F1000 Research. 2018;7:237. PMID: 29560260. Available from: 10. 12688/f1000research.12094.1.

22. Griffin DE, Lin WH, Pan CH. Measles virus, immune control, and persistence. FEMS Microbiology Reviews. 2012;36(3):649-62. PMID: 22316382. Available from: 10.1111/j.1574-6976.2012. 00330.x.

23. Klinman DM, Klaschik S, Tross D, Shirota H, Steinhagen F. FDA guidance on prophylactic DNA vaccines: analysis and recommendations. Vaccine. 2010;28(16):2801-5. PMID: 19941989. Available from: 10.1016/j.vaccine.2009.11.025.

24. Helfand RF, Kebede S, Gary HE, Beyene H, Bellini WJ. Timing of development of measles-specific immunoglobulin $\mathrm{M}$ and $\mathrm{G}$ after primary measles vaccination. Clinical and Diagnostic Laboratory Immunology. 1999;6(2):178-80. PMID: 10066650. Available from: 10.1128/CDLI.6.2.178-180.1999. 